\title{
Increasing diversity in cardiothoracic surgery: First-generation medical students
}

\author{
Justin A. Robinson, MD, ${ }^{\mathrm{a}}$ and Chi Chi Do-Nguyen, $\mathrm{DO}^{\mathrm{b}}$
}

First-generation college-graduate medical students are those whose parents have not earned a postsecondary undergraduate degree (including associates, bachelor's, master's, or doctorate). ${ }^{1}$ The mountain is steep and the climb is daunting for first-generation college graduates attending medical school, who will be termed first-generation medical students for this commentary. Up to $20 \%$ of medical students are first-generation and half of them are underrepresented minorities (URM). ${ }^{1,2}$ These individuals find that the challenges they encountered in college persist as they progress to medical school. These may include racial/ethnic discrimination, lack of work-life balance, difficulties with studying and time management, financial insecurity, feelings of imposter syndrome, and the fear of failure.

\section{CHARACTERIZATION OF FIRST-GENERATION AND CONTRIBUTIONS TO HEALTH CARE}

Despite these challenges, first-generation medical students have noteworthy qualities to offer to the field of cardiothoracic (CT) surgery. The training and lifestyle within this field requires resilience, grit, and the ability to overcome adversity. Having overcome the challenges of entering postsecondary school (eg, acquiring cultural and academic capital and finding support or mentorship), firstgeneration medical students have developed resilience and a growth mindset. Alvarado and colleagues ${ }^{3}$ performed a questionnaire among first-generation college students and their counterparts, which included the Brief Resilience Scale to qualitatively measure level of resilience. The study found that first-generation college students were more resilient than their counterparts. ${ }^{3}$ Further, a cited study by Schneider and colleagues ${ }^{4}$ demonstrated that emotional intelligence directly enhances thinking, problem solving, and

\footnotetext{
From the ${ }^{\mathrm{a}}$ Department of Cardiothoracic Surgery, University of Maryland Medical Center, Baltimore, Md; and ${ }^{\mathrm{b}}$ Department of Cardiothoracic Surgery, University of Michigan Hospitals, Ann Arbor, Mich.

Disclosures: The authors reported no conflicts of interest.

The Journal policy requires editors and reviewers to disclose conflicts of interest and to decline handling or reviewing manuscripts for which they may have a conflict of interest. The editors and reviewers of this article have no conflicts of interest.

Received for publication March 29, 2021; accepted for publication June 29, 2021; available ahead of print July 22, 2021

Address for reprints: Justin A. Robinson, MD, Department of Cardiothoracic Surgery, University of Maryland Medical Center, 611 S Charles St, Apt 643, Baltimore, MD 21230 (E-mail: robi1131@msu.edu).

JTCVS Open 2021;7:289-93

2666-2736

Copyright (C) 2021 The Author(s). Published by Elsevier Inc. on behalf of The American Association for Thoracic Surgery. This is an open access article under the CC BY-NC-ND license (http://creativecommons.org/licenses/by-nc-nd/4.0/).

https://doi.org/10.1016/j.xjon.2021.06.026
}

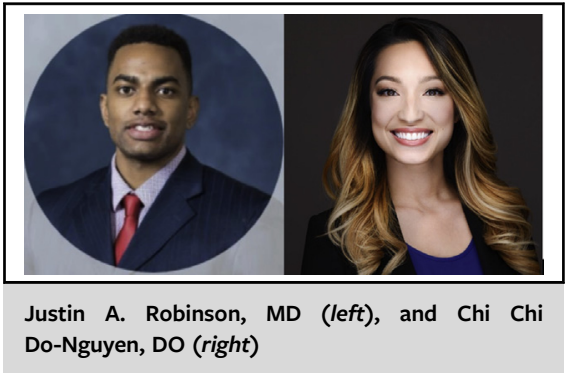

CENTRAL MESSAGE

First-generation collegegraduate medical students offer traits and contributions for better health care in cardiothoracic surgery. Those who are interested in the field may face several obstacles.

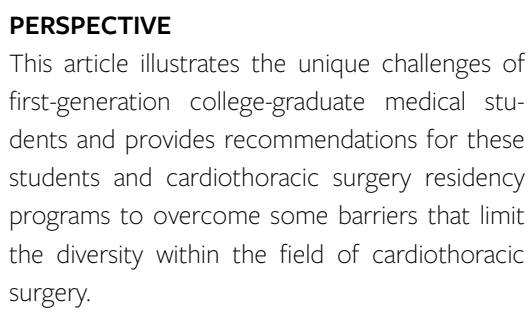

This article illustrates the unique challenges of first-generation college-graduate medical students and provides recommendations for these students and cardiothoracic surgery residency programs to overcome some barriers that limit the diversity within the field of cardiothoracic surgery.

See Commentaries on pages 294 and 295.

creativity in these individuals. These qualities can augment a growth mindset, where talents or skills can be developed by hard work, resilience, accepting feedback, and learning and growing from experiences, subsequently allowing for a more positive affect. ${ }^{3}$ These traits are helpful for CT surgeons faced with long hours, difficult and taxing surgical procedures, and the management of patients with complex cardiothoracic conditions.

Empathy, cultural competence, and an insight into health and health care disparities are also valuable qualities of first-generation medical students. ${ }^{1}$ A first-generation medical student described an experience in an article published by the Association of American Medical Colleges. ${ }^{5}$ Addressed are the striking reflections of herself and her family members in patients when they share their stories with her. She attributed her empathy and cultural competence to her 
background. ${ }^{5}$ In clinical settings, first-generation students often think of their family members who are foreign to the English language and/or the medical field, and the anxiety, distrust, and fear that comes along with it. This acknowledgment shapes the way they approach patient care, prioritizing patient trust, comfort, understanding, wellness, and medical treatment. Saha and colleagues ${ }^{6}$ found that students in more diverse US medical schools feel more prepared to care for minority populations $(61.1 \%$ vs $53.9 \% ; P<.001)$ and are more likely to advocate for equitable access to care $(54.8 \%$ vs $44.2 \% ; P<.001)$, compared with students in less-diverse medical schools. URM students are also more likely to include serving underserved populations in their future career goals $(P<.001)$, compared with White/non-White and nonURM students. ${ }^{6}$ As Romero and colleagues ${ }^{1}$ expressed, first-generation medical students "frequently consider their academic pursuits in the context of others, with personal accounts of setting aside personal interests for the greater good." These are admirable qualities in a successful CT surgeon because many studies have shown that quality of care scores that include caring behavior, competence, communication, and anticipation of needs are independent predictors of survival in patients with lung cancer, for example. ${ }^{7,8}$

Recent research has focused on the health care disparities experienced by minorities and women due to implicit bias and unique symptom presentations not widely comprehended by the medical community. ${ }^{9}$ For example, African Americans are $30 \%$ less likely to receive percutaneous coronary intervention and $40 \%$ less likely to receive coronary artery bypass grafting surgery. ${ }^{10}$ These research results have since spurred a push for more diverse health care teams because it has been shown to improve care. Varying perspectives from a diverse health care team influence patient care delivery and patients' perspective of their treatment. ${ }^{1}$ Recent studies have found that the presence of greater diversity improves the accuracy of clinical decision making. This in turn leads to better patient satisfaction and health outcomes. This is done not only by providing variety in perspectives and skills, but also by "facilitating friction that enhances deliberation and upends conformity that results in better risk assessment." ${ }^{10}$ Future efforts in diversifying health care teams can be made to include first-generation medical students.

\section{CHALLENGES IN PURSUING CT SURGERY AND A CALL TO ACTION}

Knowing these benefits, the field of CT surgery is not as diverse as it could be. From 2007 to 2017, female CT surgeons increased from $3.8 \%$ to $7.0 \% .^{9}$ From 2000 to 2013, the ratio of White to non-White CT surgeons decreased from 4.15 to $2.76 .^{9}$ Much progress has been made, but there is still a long way to go. However, amidst these diversity, equity, and inclusion efforts, the literature on the characteristics and needs of first-generation medical students endeavoring to enter CT surgery remains sparse. What are the barriers to increasing diversity, especially with first-generation medical students? The following sections will examine the challenges faced by this community and outline practical solutions.

\section{Inconsistent Definition of First-Generation and Financial Insecurity}

Recent efforts have pushed for more diversity, equity, and inclusion nationwide. These efforts have proved to be especially fruitful in CT surgery. The Society of Thoracic Surgeons Workforce on Diversity and Inclusion have worked to initiate programming to address practice gaps. ${ }^{9}$ In addition, the American Association for Thoracic Surgeons and Women in Thoracic Surgery groups collaborated to hold the annual Leadership Academy that helps minorities in the field climb the academic leadership ladder. All 3 of these national societies offer scholarships to expose students to mentors, and many initiatives have started to provide funded scholarships to URM students to explore the field. However, although half of first-generation medical students are URM, efforts have discounted the other half: Students who are not URM, but still considered first-generation. These students may experience some of the same disadvantages and experiences and are not equally advocated for in these efforts.

A uniform definition with consistency in diversity, equity, and inclusion efforts and a more focused effort in understanding this community are needed to address this problem. The definition we propose is a medical student whose parents have not earned a postsecondary undergraduate degree, which may contribute to a lack of cultural, academic, and financial capital.

Further, pursuing medical education has become a costly feat. Medical school tuition has increased $750 \%$ since the 1960 s, costing most students more than $\$ 300,000$ today. ${ }^{11}$ That is just medical school tuition alone, excluding the cost of study materials, room and board, and other various living expenses. Applying for away rotations and resident physician positions is expensive. Yet, many students who apply to CT surgery directly following medical school dual-apply to general surgery and integrated programs. That means twice the cost for away rotations, applications to residency programs, and programs to rank.

Between 1988 and 2017, 73\% to $79 \%$ of medical school matriculates came from households in the top- 2 income quintiles. ${ }^{11}$ When compared with their counterparts, firstgeneration medical students are more likely to have lower annual parent incomes. In 2002, 27\% reported $<\$ 20,000$ (vs $6 \%$ ), whereas $50 \%$ reported between $\$ 20,001$ and $\$ 50,000$ (vs $23 \%)^{1}{ }^{1}$ Further, first-generation medical students report higher levels of stress, fatigue, and financial worries, as well as lower quality of life and social support 
ratings. ${ }^{1}$ The high price of attending medical school contributes to medical students avoiding lower-paying specialties, such as primary care, or specialties with a long training course with resident salary, such as CT surgery. Addressing these financial challenges may help alleviate barriers for these students.

Scholarship efforts must expand to include all firstgeneration students, including female and URM students who fit the definition. Scholarships must be broken down into 3 categories: financial support, research, and mentorship. Financial aid scholarships should help defray the cost of exploring or applying to CT surgery. These scholarships may be based on demonstrated financial need, and help lower the cost of applying to and ranking residency programs. Specific scholarships that either offer funded clinical away rotations during students' third or fourth year of medical school or funded part-time research job opportunities will help students explore the field.

National societal scholarships could be initiated to match first-generation medical students with first-generation mentors, or mentors that are well versed in the challenges uniquely faced by these students. The Society of Thoracic Surgeons and the American Association for Thoracic Surgery have provided these types of opportunities to all medical students and residents with their Looking to the Future and Member for a Day Scholarships, respectively. These suggested opportunities will facilitate the mentorship needed to be well prepared for residency applications and beyond. What are their specific roles? The introduction of mentor scholarship opportunities would specifically aim to provide frequent (quarterly) check-ins, which would be geared toward goal-tracking, work-life balance, financial literacy, and navigating the practices of higher education that are not intuitive to first-generation medical students.

\section{CT Surgery Training Reputation Combined With a Lack of Cultural Capital}

Current medical students believe that a career in CT surgery will not provide adequate time for family and life activities, with a lack of work-life balance. ${ }^{12}$ Further, students perceived CT surgeons as having disagreeable personalities. These perceptions may be especially important for firstgeneration medical students, who may prioritize their family and work-life balance. Past literature has found that earlier interest, exposure, or recruitment efforts may result in improved perception of the field and a greater influence in successful conversion. ${ }^{13}$ Unfortunately, $75 \%$ of preclinical medical students have had no exposure to CT surgery, and as low as $21 \%$ of medical students were aware of the integrated training pathway. ${ }^{12-14}$ Medical students also have fewer opportunities for elective clinical rotations on CT surgery compared with other surgical specialties. ${ }^{14}$

Navigating the challenges in gaining exposure to CT surgery, while lacking cultural capital, is difficult. Cultural capital is defined as "knowledge, skills, education, and other advantages a person has that make the educational system a comfortable, familiar environment in which [a student] can succeed easily." 1 The lack of cultural capital among many first-generation medical students creates a barrier to getting this population adequately educated or interested in the field.

Programs aimed at increasing education regarding the field of CT surgery are necessary for this population. Women in Thoracic Surgery and the Society of Black Academic Surgeons, for example, are organizations designed to enhance educational opportunities, advance science, and provide mentorship for women, African Americans, and other underrepresented minority surgeons. Due to the limited number of first-generation medical students interested in CT surgery, a nationwide first-generation group would be more effective than regional or local groups. With similar goals to Women in Thoracic Surgery and the Society of Black Academic Surgeons, a firstgeneration national society should be designed to mentor, provide educational opportunities, assist with career development, and increase the number of first-generation CT surgeons. This will, in effect, create a safe space for first-generation students, amplify their presence, and foster a robust environment to increase understanding and interest in CT surgery. As a start, this initiative could be created as a committee of the Thoracic Surgery Medical Student Association.

\section{Discriminative Application Process}

The residency application process was not made for the first-generation medical student. Financial dilemmas aside, many metrics disadvantage these students. The first item that a residency selection committee sees on an application is the individual's name. However, Esmail and colleagues ${ }^{15}$ found that if the same application was sent to physician job postings with an English name versus an Asian name, English applicants were twice as likely to be offered the job. Further, first-generation medical students experience stereotype threat more than their counterparts $(P=.014) .{ }^{16}$ They have associated their status in negatively stereotyped groups with increased anxiety in regard to clinical rotation performance, standardized tests, and writing skills $(P<.001)$, all of which are important aspects of the residency application process. Another important aspect is extracurricular activities in medical school. However, Seay and colleagues ${ }^{17}$ found that first-generation students are more likely to drop out due to a lack of engagement with on-campus activities and lack of interaction outside of the classroom with faculty and mentors. Many first-generation students acknowledge that this can be explained by the need to work to support family members. These limitations must be considered during the residency selection process. 
In CT surgery, half of integrated applicants decide to pursue a career before or during their preclinical years of medical school. ${ }^{18} \mathrm{~A}$ strong, well-rounded application is crucial to successfully match. Successful applicants listed mentorship (89\%), previous clinical exposure (98\%), and research experience $(72 \%)$ as being important factors in pursuing their career path. ${ }^{18}$ To compete for the highly competitive residency spots in integrated programs, students must align their research, clinical rotations, standardized testing, and mentorship goals early. ${ }^{12}$ The lack of cultural capital of first-generation medical students leads to an absence of knowledge of various educational pathways, such as the integrated $4+3$, versus traditional pathways. ${ }^{3}$ It can also affect knowledge surrounding how the residency application process works, study habits, university resources, research opportunities, and psychological and emotional strategies to overcome challenges. ${ }^{3}$ But these students could gain cultural capital throughout medical school and residency and then apply through the traditional pathway, right? For those pursuing cardiothoracic surgery through the traditional route (after general surgery training), there is a general lack of exposure to cardiac surgery cases because only $4 \%$ of total residency cases are considered CT surgeries and of those, only $7.3 \%$ are cardiac cases. ${ }^{14}$

To combat the stereotype threat previously mentioned, a holistic review of the residency application by residency selection committees is recommended. After the initial screening process, this can be done by blinding applicants' names, photos, medical school names, and board scores to decrease discrimination and emphasis on the application aspects that may have stereotype threat. Further, it is recommended to consider work experiences in its context with equal importance as volunteer, leadership, and research experiences. This recommendation may benefit applicants beyond those who identify as first-generation medical students.

As mentioned previously, the cost of medical education is costly and first-generation medical students are more likely to come from lower-income households. Financial literacy and wealth are major concerns among this group, which may subsequently lead to insufficient financial planning and funds for residency applications (an average cost of \$3500). ${ }^{19}$ To tackle this issue, residency programs may consider continuing, at least partially, with the virtual

TABLE 1. Recommendations for increasing diversity in cardiothoracic surgery with first-generation college-graduate medical students

\begin{tabular}{|c|c|c|}
\hline Challenge & Advice for students & Recommendations for residency programs \\
\hline $\begin{array}{l}\text { Inconsistent definition } \\
\text { of first-generation }\end{array}$ & \multicolumn{2}{|c|}{$\begin{array}{l}\text { First-generation medical student: A medical student whose parents have not earned a postsecondary undergraduate } \\
\text { degree, which may contribute to a lack of cultural, academic, and financial capital }\end{array}$} \\
\hline Financial insecurity & $\begin{array}{l}\text { 1. Do your own research } \\
\text { 2. Talk to school financial advisors } \\
\text { 3. Make a budget and have it reviewed by } \\
\text { financially literate individuals on a quarterly } \\
\text { basis }\end{array}$ & $\begin{array}{l}\text { Increase inclusive funded scholarships } \\
\text { 1. Need-based scholarships to help apply for and rank } \\
\text { residency programs } \\
\text { 2. Funded clinical away rotation programs for third- } \\
\text { /fourth-year medical students } \\
\text { 3. Funded programs for mentorship and exposure } \\
\text { 4. Funded part-time research job opportunities }\end{array}$ \\
\hline $\begin{array}{l}\text { Training reputation and } \\
\text { lack of cultural capital }\end{array}$ & $\begin{array}{l}\text { 1. Find mentors through various societal conferences } \\
\text { (ie, Society of Thoracic Surgeons, American } \\
\text { Association for Thoracic Surgery) } \\
\text { 2. Talk to residents of cardiothoracic surgery training } \\
\text { programs }\end{array}$ & $\begin{array}{l}\text { Increase education regarding the field of cardiothoracic } \\
\text { surgery } \\
\text { 1. Start of a nationwide first-generation medical student } \\
\text { society in cardiothoracic surgery } \\
\text { 2. Create a first-generation committee of the Thoracic } \\
\text { Surgery Medical Student Association }\end{array}$ \\
\hline $\begin{array}{l}\text { Discriminative residency } \\
\text { application process }\end{array}$ & $\begin{array}{l}\text { 1. Plan early to learn about the residency application } \\
\text { process } \\
\text { 2. Talk to the program directors at schools of interest } \\
\text { to get insight on the process } \\
\text { 3. Budget early for the finances of away rotations and } \\
\text { applications }\end{array}$ & $\begin{array}{l}\text { Make the process first-generation friendly } \\
\text { 1. Blinding of application for residency selection } \\
\text { committees } \\
\text { 2. Funding for the application process } \\
\text { 3. Continuation of virtual interviews, with provided } \\
\text { background templates } \\
\text { 4. Interview workshops for applicants to provide advice, } \\
\text { and residency selection committees to provide } \\
\text { unconscious bias training }\end{array}$ \\
\hline Personal well-being & $\begin{array}{l}\text { 1. Create healthy habits/hobbies and make them a priority } \\
\text { 2. Find a supportive network (ie, family, friends, } \\
\text { significant other) } \\
\text { 3. Prioritize rest and relaxation }\end{array}$ & $\begin{array}{l}\text { Promote personal wellness } \\
\text { 1. Finances and budgeting workshops } \\
\text { 2. Health and wellness seminars } \\
\text { 3. Mandatory personal wellness day(s) }\end{array}$ \\
\hline
\end{tabular}


format of the interview process and provide the same background templates for all interviewees. This would create an equitable field and significantly reduce the financial burden.

\section{Personal Wellness}

Further, residency programs can directly support firstgeneration medical students in many ways. They can address feelings of inadequacy by offering counseling services that address life and financial stressors, selfpreservation strategies, work-life balance, life-changing events, and mental health and wellness. Specifically, enrichment programs tailored to first-generation students that offer career guidance, tutoring, financial aid information, and/or college adjustment workshops may be initiated at graduate institutions. For example, America Needs You is a nonprofit that seeks to help economically disadvantaged first-generation students reach their potential through mentored and career development programs.

Although targeting first-generation medical students is not the only way to increase diversity because some of these challenges could be shared by doctor of osteopathy students, foreign medical graduates, and those of different religion, gender, and sexual identities, it is a start. By identifying some barriers, solutions can be continually created to provide insight into strategies of success, decrease potential attrition, and ensure the continual recruitment of the best and the brightest into the field of CT surgery (Table 1).

\section{CONCLUSIONS}

First-generation medical students exhibit many of the traits necessary for success in CT surgery. However, those who are interested in or applying to the field face unique challenges. Understanding these challenges and creating initiatives to support first-generation medical students will ensure we continue to recruit the best and the brightest, and enhance patient care in the field of CT surgery.

\section{References}

1. Romero R, Miotto K, Casillas A, Sanford J. Understanding the experiences of first-generation medical students: implications for a diverse physician workforce. Acad Psychiatry. 2020;44:467-70.

2. Mason. First-generation medical student wellness in the United States: a crosssectional snapshot. J Best Pract Health Prof Divers. 2019;11:96-106.

3. Alvarado A, Spatariu A, Woodbury C. Resilience and emotional intelligence between first generation college students and non-first generation college students. Focus Coll Univ School. 2017;11:1-10.

4. Schneide TR, Lyons JB, Khazon S. Emotional intelligence and resilience. Pers Individ Dif. 2013;55:909-14.

5. Association of American Medical Colleges. Finding success as a first-generation medical student. Available at: https://www.aamc.org/news-insights/findingsuccess-first-generation-medical-student. Accessed May 5, 2021.

6. Saha S, Guiton G, Wimmers PF, Wilkerson L. Student body racial and ethnic composition and diversity-related outcomes in US medical schools. JAMA 2008;300:1135-45

7. Doering LV, McGuire AW, Rourke D. Recovering from cardiac surgery: what patients want you to know. Am J Crit Care. 2002;11:333-43.

8. Subramanian M, Kozower BD, Brown LM, Khullar OV, Fernandez FG. Patient-reported outcomes in cardiothoracic surgery. Ann Thorac Surg. 2019;107:294-301.

9. Corsini EM, Olive J, Antonoff MB. The current status and importance of diversity in cardiothoracic surgery. Curr Surg Rep. 2020;8:19.

10. Gomez LE, Bernet P. Diversity improves performance and outcomes. J Natl Med Assoc. 2019;111:383-92.

11. STAT. Medical schools need to lower the cost of producing doctors. Available at: https://www.statnews.com/2020/07/21/lower-cost-producing-doctors-not-just-pricemedical-school. Accessed May 5, 2021.

12. Coyan GN, Kilic A, Gleason TG, Schuchert MJ, Luketich JD, Okusanya O, et al Medical student perceptions of a career in cardiothoracic surgery: results of an institutional survey. J Thorac Cardiovasc Surg. 2020;159:1906-12.

13. Sood V, Reddy RM. An analysis of preclinical students' perceptions of cardiothoracic surgical procedures. Ann Thorac Surg. 2012;94:800-6.

14. Kilcoyne MF, Do-Nguyen CC, Han JJ, Coyan GN, Sultan I, Roberts MB, et al. Clinical exposure to cardiothoracic surgery for medical students and general surgery residents. J Surg Educ. 2020;77:1646-53.

15. Esmail A, Everington S. Racial discrimination against doctors from ethnic minorities. BMJ. 1993;306:691-2.

16. Ackerman-Barger K, Valderama-Wallace C, Latimore D, Drake C. Stereotype threat susceptibility among minority health professions students. J Best Pract Health Prof Divers. 2016;9:1232-46.

17. Seay SE, Lifton DE, Wuensch KL, Bradshaw LK, McDowelle JO. First-generation graduate students and attrition risks. J Continu Higher Educ. 2008;56: 11-25.

18. Smood B, Nguyen SN, Kelly JJ, Han JJ. Integrated cardiothoracic surgery: developing a successful residency application. J Thorac Cardiovasc Surg. 2020;160: 167-74.

19. Walling A, Nilsen K, Callaway P, Grothusen J, Gillenwater C, King S, et al. Student expenses in residency interviewing. Kans J Med. 2017;10:1-15. 